\title{
Degassing patterns of Tungurahua volcano (Ecuador) during the 1999-2006 eruptive period, inferred from remote spectroscopic measurements of $\mathrm{SO}_{2}$ emissions
}

\author{
S.R. Arellano ${ }^{\text {a,* }}$, M. Hall ${ }^{\text {a }}$, P. Samaniego a , J.-L. Le Pennec ${ }^{\text {b }}$, A. Ruiz ${ }^{\text {a }}$, I. Molina ${ }^{\text {a }}$, H. Yepes ${ }^{\text {a }}$ \\ a Instituto Geofísico, Escuela Politécnica Nacional, P.O. Box 17-01-2759, Quito, Ecuador \\ b IRD, UMR 163, Laboratoire Magmas et Volcans, 5 rue Kessler, 63038 Clermont-Ferrand, France
}

\section{A R T I C L E I N F O}

\section{Article history:}

Received 13 March 2007

Accepted 3 July 2008

Available online $\mathrm{xxxx}$

\section{Keywords:}

sulfur dioxide

volcanic degassing

COSPEC

DOAS

Tungurahua volcano

\begin{abstract}
A B S T R A C T
This paper presents the results of 7 years (Aug. 1999-Oct. 2006) of $\mathrm{SO}_{2}$ gas measurements during the ongoing eruption of Tungurahua volcano, Ecuador. From 2004 onwards, the operation of scanning spectrometers has furnished high temporal resolution measurements of $\mathrm{SO}_{2}$ flux, enabling this dataset to be correlated with other datasets, including seismicity. The emission rate of $\mathrm{SO}_{2}$ during this period ranges from less than 100 to 35,000 tonnes/day $\left(\mathrm{t} \mathrm{d}^{-1}\right)$ with a mean daily emission rate of $1458 \mathrm{t} \mathrm{d}^{-1}$ and a standard deviation of $\pm 2026 \mathrm{t} \mathrm{d}$. Average daily emissions during inferred explosive phases are about 1.75 times greater than during passive degassing intervals. The total amount of sulfur emitted since 1999 is estimated as at least $1.91 \mathrm{Mt}$, mostly injected into the troposphere and carried westwards from the volcano. Our observations suggest that the rate of passive degassing at Tungurahua requires $\mathrm{SO}_{2}$ exsolution of an andesitic magma volume that is two orders of magnitude larger than expected for the amount of erupted magma. Two possible, and not mutually exclusive, mechanisms are considered here to explain this excess degassing: gas flow through a permeable stagnantmagma-filled conduit and gas escape from convective magma overturning in the conduit. We have found that real-time gas monitoring contributes significantly to better eruption forecasting at Tungurahua, because it has provided improved understanding of underlying physical mechanisms of magma ascent and eruption.
\end{abstract}

(c) 2008 Elsevier B.V. All rights reserved.

\section{Introduction}

Understanding the modalities of volcanic degassing is crucial for a thorough evaluation of the timing and nature of eruptive processes and their impact on atmospheric chemistry and climate (Robock, 2000; Oppenheimer, 2003; Sparks, 2003). This task is a challenge for volcanologists who must consider gas transportation processes related to volatile content in parental magmas, exsolution and migration of gas species through volcanic pathways, and their subsequent emission and aerial dispersion. Most degassing models explain these processes based upon the correlation of different time-series data coming from the growing 'paraphernalia' of monitoring techniques, which typically consist of seismic, geodetic and geochemical methods. However, correlation of continuous (e.g., seismic observations) with intermittent (e.g., traditional gas monitoring data) time-series data limits a complete understanding of eruptive processes. As such, automated systems for continuous geochemical surveillance are of great importance (Galle et al., 2002; Edmonds et al., 2003b).

This paper presents an especially continuous record of measurements of $\mathrm{SO}_{2}$ emissions from Tungurahua volcano from August 1999 to October 2006 obtained through Correlation Spectroscopy -COSPEC-

\footnotetext{
* Corresponding author. Tel.: +593 2 2225655; fax: +5932 2567847

E-mail address: sarellano@igepn.edu.ec (S.R. Arellano).
}

(Moffat and Millán, 1971), and Differential Optical Absorption Spectroscopy -DOAS- (Platt, 1994) techniques. The more recently acquired minute-scale resolution of the DOAS method allows us to correlate gas emission rates with other datasets, such as seismicity, with unprecedented detail, and gives us some reliable insights into the mechanisms responsible for magma degassing at Tungurahua Volcano. We provide both an estimate of the volume of sulfur released to the atmosphere and implications for the environmental impact of the current eruption.

\section{Tungurahua Volcano: eruptive history and current monitoring}

Tungurahua is a large (12 km in diameter, $5023 \mathrm{~m}$ a.s.l.) andesitic stratovolcano located in the Eastern Cordillera of the Ecuadorian Andes about $120 \mathrm{~km}$ south of Quito (see Fig. 1). According to Hall et al. (1999), Tungurahua is composed of three successive volcanic edifices, separated by huge sector collapses. The young edifice was constructed inside a horse-shoe shaped caldera open to the west following the last sector collapse dated at $\sim 3000$ y BP. During the last 2300 years, the magma supply rate has been estimated at $\sim 1.5 \times 10^{6} \mathrm{~m}^{3} \mathrm{y}^{-1}$ (Hall et al., 1999). As such, it ranks among the most active volcanoes of the Andes, averaging at least one eruption per century (Hall et al., 1999; Samaniego et al., 2003; Le Pennec et al., 2008-this issue). During historical times (i.e., after $1532 \mathrm{AD}$ ), Tungurahua has experienced at least four eruptive cycles occurring around 1640, 1773, 1886 and 19161918 (Martínez, 1886, 1932; Le Pennec et al., 2008-this issue). These 


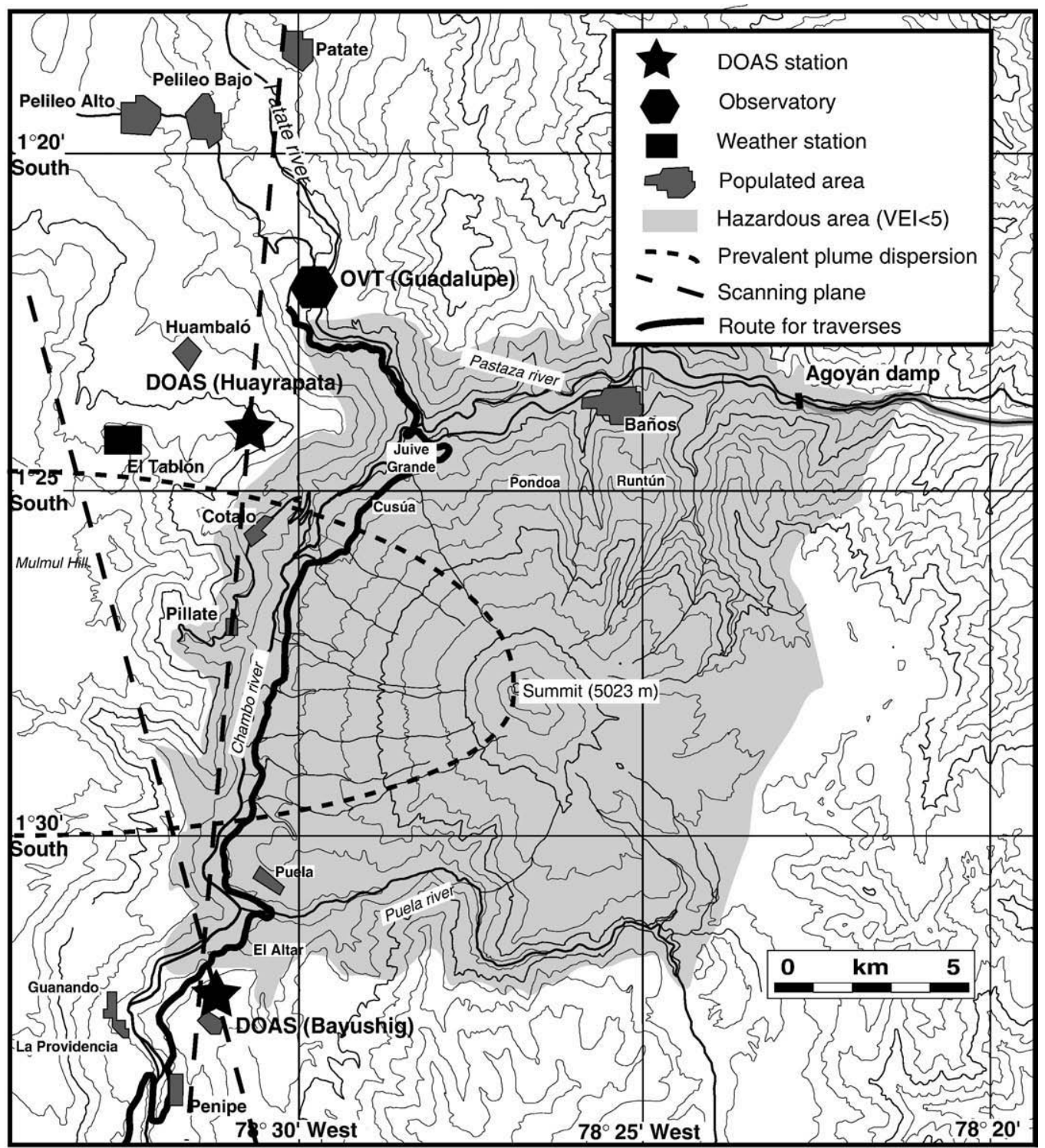

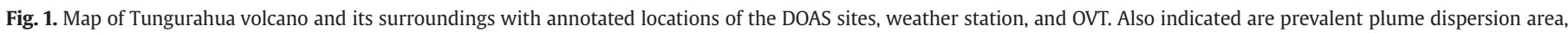
DOAS scanning planes, and typical traverse route.

eruptions have produced lava flows, pyroclastic flows, ash falls, debris flows, and lahars. The eruptive period which started in 1999, has produced two explosive eruptions on 14 July and on 16-17 August 2006, which have threatened the growing populations located on the lower northern, western, and southern flanks of the volcano, particularly in the tourist town of Baños ( 18,000 inhabitants) at the northern foot of the mountain. A comprehensive hazard map for Tungurahua was published by Hall et al. (2002) and highlights the significant hazards posed by this volcano.

Tungurahua volcano has been monitored since 1988 by the Instituto Geofisico de la Escuela Politécnica Nacional (IGEPN) through seismological, geochemical, thermal, geodetic, acoustic, and other observational techniques. According to IGEPN reports (synthesized in Samaniego et al., 2003), between 1994 and 1997 important hydrothermal tremor was detected, which was associated with strong rainfall periods (Ruiz et al., 1999). From September 1998 to July 1999 seismic activity, which included tremor, swarms of volcano-tectonic earthquakes (VT), and deep long period signals ( $\mathrm{LP},>5 \mathrm{~km}$ below the summit), as well as the emission of steam columns, suggested the ascent of magma. The initial $\mathrm{SO}_{2}$ measurements $\left(\sim 2300 \mathrm{t} \mathrm{d}^{-1}\right.$; where $\left.1 \mathrm{t} \mathrm{d}^{-1}=1.1574 \times 10^{-2} \mathrm{~kg} \mathrm{~s}^{-1}\right)$ were obtained in August 1999. $\mathrm{SO}_{2}$ flux peaked at $\sim 10,000 \mathrm{t} \mathrm{d}^{-1}$ in October 1999 when magma reached the crater.
Between October 1999 and October 2006, Tungurahua alternated between explosive periods, characterized by both Strombolian and Vulcanian activity, and relatively quiet intervals manifested by weak steam and ash emissions or total quiescence. Relatively intense activity occurred in October-November 1999, August 2000, August 2001, September 2002, November 2003, May-July 2004, and May-August 2006, while pyroclastic-flow-forming events took place on 14 July and 16-17 August 2006 (Fig. 2).

The two explosive eruptions in 2006 were preceded by a notable increase in seismic energy release during the previous three months, as well as a change of the deformation pattern. The 14 July eruption was a moderate-sized event (Volcanic Explosivity Index -VEI- =2) that generated pyroclastic flows that descended the main gullies on the NE, $\mathrm{N}$, and $\mathrm{W}$ flanks. The estimated dense rock equivalent (DRE) volume of magma erupted during this event is about $10^{6} \mathrm{~m}^{3}$ with an associated $\mathrm{SO}_{2}$ total discharge of about $12,000 \mathrm{t}$, measured by the Ozone Monitoring Instrument -OMI- (Carn et al., 2008-this issue). The 16-17 August eruption was more explosive $(\mathrm{VEI}=3)$. Its paroxysmal phase, which started at $05 \mathrm{~h} 30$ UTC on 17 August and lasted for about $50 \mathrm{~min}$, was preceded by about $16 \mathrm{~h}$ of uninterrupted tremor of increasing seismic amplitude, tephra fallout, and loud audible rumbling. This event produced a $20 \mathrm{~km}$-high eruption column and numerous 


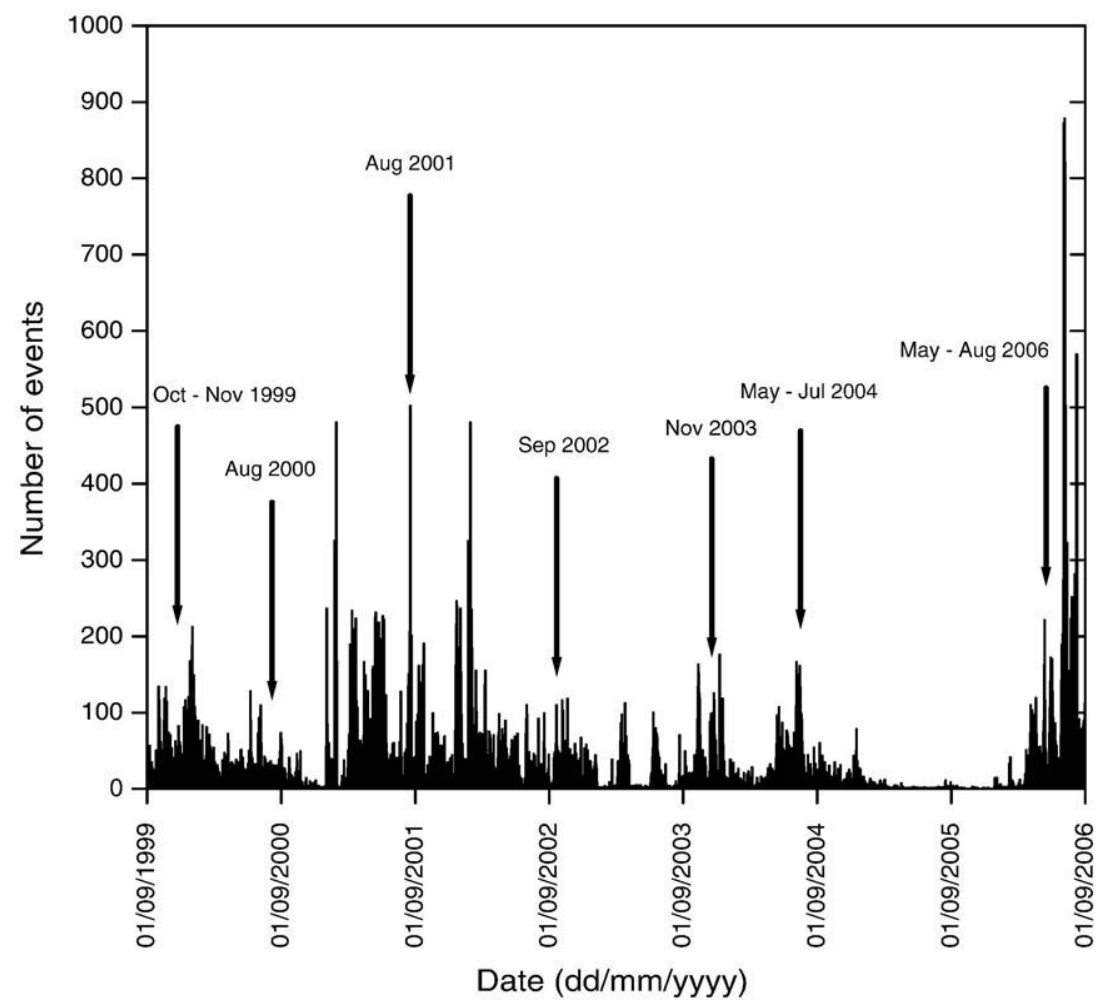

Fig. 2. Tungurahua seismicity recorded during the 1999-2006 eruptive period. Periods of high eruptive activity are indicated with dates.

pyroclastic flows that descended the principal gullies on the $\mathrm{N}, \mathrm{W}$, and SW flanks of the volcano and temporarily dammed the Puela, Chambo, and Pastaza rivers. A lava flow, the first observed since the beginning of the eruptive cycle in 1999, descended the NW flank of the cone just after the explosive phase. The volume of magma erupted in the 16-17 August event is estimated at $2 \times 10^{7} \mathrm{~m}^{3}$ (DRE), and OMI measurements put the $\mathrm{SO}_{2}$ discharge at 35,000 t (Carn et al., 2008-this issue). Immediately after this eruption, volcanic activity declined abruptly, showing a slight increase during October 2006. During these months, $\mathrm{SO}_{2}$ flux measurements, as well as seismic energy release, suggested the persistence of a shallow magma body.

\section{Spectroscopic remote sensing techniques used in this study}

\subsection{COSPEC}

Since 1988, the IGEPN has been made spectroscopic remote measurements of volcanogenic $\mathrm{SO}_{2}$ on several Ecuadorian volcanoes, using a Barringer Research Correlation Spectrometer (COSPEC) V. COSPEC data at Tungurahua have been obtained by stationary and groundbased/airborne traverse techniques (Moffat and Millán, 1971; Stoiber et al., 1983; McGonigle and Oppenheimer, 2003).

Measurements by the stationary or scanning mode were normally done from a site known as 'Cruz de Cotaló' (2800 m a.s.l., see Fig. 1), located about $5 \mathrm{~km} \mathrm{NW}$ of the volcano's summit. Car traverses were possible during different stages of the present eruptive period, taking advantage of a road around the western flank of the volcano (see Fig. 1). Typical COSPEC acquisition parameters are shown in Table 1.

\subsection{DOAS and mini-DOAS}

Because of persistent cloudy conditions and difficult access to acceptable scanning sites due to inconvenient plume dispersal directions (e.g., the East and South quadrants of the volcano), COSPEC monitoring resulted in sparse $\mathrm{SO}_{2}$ measurements. Thus, a DOAS-based automatic scanner was installed by IGEPN to more continuously monitor the $\mathrm{SO}_{2}$ emission rate at Tungurahua. The employed instrumentation, installed in June 2004, is a variant of the Montserrat Volcano Observatory (MVO) 'Scanspec' system (Edmonds et al., 2003b) that is hereafter referred to as the DOAS system. This instrument uses the Multi-Axis DOAS configuration (Hönninger et al., 2004) to acquire scattered UV solar radiation spectra.

Two DOAS stations were emplaced at 9.1 and $11.9 \mathrm{~km}$ from the volcano's summit at the sites called Huayrapata and Bayushig, respectively (see Fig. 1), and are $15.5 \mathrm{~km}$ apart. The prevailing easterly winds direct the volcanic plume through the N-S scanning path of the DOAS instruments. The system is remotely controlled from the observatory (Observatorio del Volcán Tungurahua -OVT-, see Fig. 1) and acquires UV radiation spectra controlled by the 'DOAS' software developed by MVO scientists. About 10,000 spectra are collected daily during sunlight hours (typically from $08 \mathrm{~h} 00$ to $16 \mathrm{~h} 00$ local time). Data is then processed by using the in-house 'DOASIG'software, which runs in Matlab®. This program uses a relative DOAS method (see Section 4.1) and applies a single-scattering radiative transfer model to avoid the non-negligible effect of clouds upon these types of spectroscopic measurements (Millán, 1980; Pfeilsticker et al., 1998). A Gaussian advection-diffusion model is also incorporated in the code for better constraining the plume geometry. Through this procedure it is possible to estimate integrated $\mathrm{SO}_{2}$ emission rates utilizing only one scanning instrument (Arellano et al., 2006).

A portable spectrometer, hereafter referred to as the mini-DOAS, is used when the plume is not swept by the permanent scanners. It is operated as part of a traverse to conduct more specific studies regarding plume advection and dynamics (Galle et al., 2002; McGonigle et al., 2002). Typical DOAS and mini-DOAS acquisition parameters are listed in Table 1.

\subsection{Satellite-based sensors}

In addition to the ground-based techniques, important information about the emission and dispersion of volcanic gases has been obtained from satellite-based instruments including the Total Ozone 
Table 1

Inter-comparison of specifications of COSPEC V, DOAS, and mini-DOAS systems used for monitoring $\mathrm{SO}_{2}$ output at Tungurahua

\begin{tabular}{|c|c|c|c|}
\hline & COSPEC V & DOAS & Mini-DOAS \\
\hline Weight (kg) & 42 & 8 (excluding solar panels) & 0.4 (excluding laptop) \\
\hline Power (W) & 8 (from $12 \mathrm{~V}$ car battery) & $\begin{array}{l}6.89 \text { from car battery and solar panels } \\
\text { (including stepper motor, transmitter and repeater radios) }\end{array}$ & 0.45 from computer USB port \\
\hline $\begin{array}{l}\text { Dimensions } \\
(\mathrm{mm} \mathrm{L} \times \mathrm{W} \times \mathrm{H})\end{array}$ & $\begin{array}{l}1023 \times 533 \times 227 \\
\text { (including carrying case) }\end{array}$ & $400 \times 250 \times 500$ (including waterproof enclosure) & $89 \times 63 \times 34$ (excluding laptop and telescope) \\
\hline $\begin{array}{l}\text { Minimum } \\
\text { detection limit }\end{array}$ & $\begin{array}{l}2.5 \mathrm{ppm} \mathrm{m} \text { at } 8 \mathrm{~s} \text { integration time } \\
(1: 1 \mathrm{~S} / \mathrm{N})^{\mathrm{a}}\end{array}$ & $2.5 \mathrm{ppm} \mathrm{m}$ at $3 \mathrm{~s}$ integration time $(3 \sigma)^{\mathrm{a}}$ & $2.5 \mathrm{ppm} \mathrm{m}$ at $3 \mathrm{~s}$ integration time $(3 \sigma)^{\mathrm{a}}$ \\
\hline Detector & PMT R663 & 2048 element linear CCD (SONY® ILX511) & 2048 element linear CCD (SONY® ILX511) \\
\hline Slit width $(\mu \mathrm{m})$ & & 50 & 50 \\
\hline Resolution (nm) & 0.2 & $\sim 0.44$ & $\sim 0.44$ \\
\hline Foreoptics & Cassegrain telescope & $\begin{array}{l}4 \text { fiber bundle }+2 \text { lens, stepper motor-based scanning } \\
\text { telescope }\end{array}$ & 4 fiber bundle +1 lens, UV band pass filter telescope \\
\hline Field of view (mrad) & $10 \times 30$ & 20 & 20 \\
\hline $\begin{array}{l}\text { Acquisition software or } \\
\text { method }\end{array}$ & COSPEC V analogical recorder & MVO-DOAS software & In-house script for $D O A S I S \circledR$ version 2.07.02.09 \\
\hline Processing method & Manual counting of analogical record & In-house software written in $M a t L a b \circledast$ & In-house software written in $M a t L a b \circledast$ \\
\hline Spectral range & $300-315$ & $278-480$ & $278-434$ \\
\hline Fit window (nm) & $300-315$ & $305-314$ & $304-313$ \\
\hline Reference spectra & $\begin{array}{l}\text { In situ, using } 102 \text { and } 315 \text { ppm m } \\
\text { calibration cells }\end{array}$ & $\begin{array}{l}\text { Laboratory reference }{ }^{\mathrm{b}} \text { convoluted to the spectrometer } \\
\text { resolution }\end{array}$ & $\begin{array}{l}\text { Laboratory reference }{ }^{\mathrm{b}} \text { convoluted to the } \\
\text { spectrometer resolution }\end{array}$ \\
\hline $\begin{array}{l}\text { Typical integration time } \\
\text { (ms) }\end{array}$ & 1000 & $370 \times 4$ (exposure time $\times$ number of co-added spectra) & $\begin{array}{l}(50-1000) \times(4-10) \text { (range of exposure time } \times \text { range } \\
\text { of number of co-added spectra) }\end{array}$ \\
\hline
\end{tabular}

\footnotetext{
a Galle et al., 2002.
}

b Vandaele et al., 1994.

Mapping Spectrometer and (TOMS) and OMI. Importantly, $\mathrm{SO}_{2}$ output from the explosive eruptions of July and August 2006, which occurred at night, was only detected by OMI. This instrument acquires measurements on a daily basis and its results agree satisfactorily with those obtained with the techniques operated by the IGEPN (Carn et al., 2008-this issue).

\section{Data retrieval strategies and error analysis}

To calculate the gas flux from an erupting volcano, we consider several different variables including column density, and plume dimension and dispersion. Each of these quantities is subject to measurement and processing uncertainties summarized below.

\subsection{Column density}

Analysis of COSPEC data collected by IGEPN is performed by the standard counting process of an analogical chart record described in Stoiber et al. (1983). A mask correlation spectroscopic measurement (Moffat and Millán, 1971) provides the column density (usually expressed as a concentration path-length in $\mathrm{ppm} \mathrm{m}$ ) of the absorbing molecules (i.e., $\mathrm{SO}_{2}$ ) present in the portion of the plume scanned by the instrument. The total gas column density is determined by integrating the area recorded in a paper chart after performing a full scan over a cross section of the plume. This is the most widespread method used by volcanologists since the 1970 s to measure the $\mathrm{SO}_{2}$ gas burden in the plume. Shortcomings of this method include the potential overestimate of the gas concentration due to scattering effects (Millán, 1980), and eventual errors produced in the counting process of the recorded chart, which depends upon the operator's expertise.

The DOAS system revolves $360^{\circ}$ around a horizontal axis sweeping through the sky in a vertical plane. Each spectrum is first classified as 'dark' (noisy, unexposed to skylight, down-looking scan) or 'sky' (exposed to skylight, up-looking scan), according to the level of radiation intensity measured in the spectral range of interest (see Table 1). For the sky measurements, a single-scattering Radiative Transfer Model (RTM) is applied. This model assumes that a Lambertian surface is present above the plume, acting as a first-order scattering layer, as proposed by Hönninger et al. (2004) for Multi-AXis DOAS (MAX-DOAS) measurements. Our model involves a different geometrical solution following Arellano et al. (2006), in which slant column densities $(S)$ are converted to vertical column densities $(V)$, according to the Air Mass Factor (AMF) calculated with Eq. (1).

$$
A M F=\frac{S}{V}=\left[\frac{a}{\sin \alpha}+\sqrt{\left(\tan \gamma-\frac{a \cos \delta}{\tan \alpha}\right)^{2}+(1-a)^{2}+\left(\tan \sigma-\frac{a \sin \delta}{\tan \alpha}\right)^{2}}\right]
$$

Where $a$ represents the relative height of the effective scattering layer in the atmosphere computed as a factor between 0 (ground level) and 1 (top of the atmosphere). The value of $a$ is found by looking for the best fit between the theoretical and measured radiation intensities detected by the instrument under ideal conditions (aerosols-free atmosphere). We have found that this parameter changes during the day, following a trend that can be approximated by a function that increases linearly from sunrise to local noon, and then decreases linearly until sunset. The parameter $\alpha$ is the elevation or scanning angle of the instrument, $\gamma$ corresponds to the inclination angle of the solar plane in the sky and is latitude-dependant, $\delta$ represents the scan azimuth angle, and $\sigma$ is the solar elevation angle (time-dependant). These variables are shown schematically in Fig. 3 and listed in Table 2.

The application of this RTM seeks to reconstruct the intensity of the UV spectra acquired under aerosol-free atmospheric conditions. Significant attenuation (more than $50 \%$ of the theoretical value) of the measured radiation intensity using the same acquisition parameters within a full scan is attributed to scattering produced by water vapor clouds; consequently, these data are discarded. This simple procedure has produced encouraging results, however, it is only used for detecting and removing cloud-affected data. It is not utilized in the subsequent DOAS retrieval process in order to avoid possible artefacts.

The 'classical' method to obtain column densities from absorption spectroscopy measurements requires dividing the in-plume spectrum by the off-plume or background spectrum, following removal of noise. A complication in automatic scanning measurements, like those deployed in our DOAS system, is selecting an appropriate background signal. For the MVO Scanspec system, Edmonds et al. (2003b) proposed a trial-anderror procedure that can be time-consuming for processing large datasets. Instead, we have developed a 'relative' method in which the total column is obtained by adding partial column abundances corresponding to the sum of the relative absorption between two consecutive spectra (positive, negative or null) and the last 'absolute' measurement. Here the relative absorption between the first and second sky spectra, i.e., the first scans over the horizon, is considered as the first absolute measurement. 
Table 2

Variables used to calculate the Air Mass Factor used for processing DOAS data

\begin{tabular}{lll}
\hline $\begin{array}{l}\text { Symbol } \\
\text { (units) }\end{array}$ & Range of variation & Description \\
\hline$a$ & $0.2-0.4^{\mathrm{a}}$ & Relative altitude of effective scattering layer \\
$\alpha\left({ }^{\circ}\right)$ & $0-180^{\mathrm{b}}$ & Scan angle \\
$\gamma\left({ }^{\circ}\right)$ & $23.5-L$ to $-23.5-L^{\mathrm{c}}$ & Latitudinal variation of solar plane angle \\
$\delta\left({ }^{\circ}\right)$ & $0-360$ (clockwise) & Scan azimuth \\
$\sigma\left(^{\circ}\right)$ & 90 to -90 (E to W) & Solar hour angle \\
\hline
\end{tabular}

a Linear variation in time according to empirical fitting of data under clear-sky conditions.

b Time of each step is equal to spectrometer's exposure time.

c $L$ represents latitude of station.

Each of the partial column abundances is converted to a vertical column according to its scan angle. The sequence finishes when a dark spectrum is detected. If a negative offset in column density is detected, its absolute value is added to each individual column density. Finally, the plume boundary angles are determined.

The differential absorption algorithm is performed by using a Matlab ${ }^{\circledR}$ elliptical filter, whereas the fitting validation is evaluated through correlation of the processed spectrum with the reference laboratory spectrum. Also, a correction for the change in the relation between the spectrometer's pixel numbers and the correspondent wavelengths is also carried out to avoid a potential thermally-induced anomaly.

For mini-DOAS measurements, we process data in real-time by using standard DOAS algorithms incorporated in the DOASIS ${ }^{\circledR}$ software (http://www.iup.uni-heidelberg.de/bugtracker/projects/doasis). The differential absorption spectra are then evaluated by an in-house code, which also runs in Matlab ${ }^{\circledR}$, applying the above-mentioned shifting and fitting routines.

\subsection{Plume dimensions and dispersion}

Estimation of the plume width is trivial when the measurements are performed in traverse mode (involving a perpendicular interception of the plume), but measurements from fixed-stations require consideration of other variables such as the plume boundary angles, the plume-instrument distance, and the optical field of view. Additional information about the wind direction and speed at the altitude of the plume axis (i.e., the trajectory of principal absorption) can be used to calculate the distance from the instrument to the plume axis as well as the plume height. When the scan angles at which the plume is detected are very low, this calculation produces unreliable results for the plume geometry, and our code will then calculate the plume width based on a Gaussian advectiondiffusion model (Bursik, 1998, pp. 124). This model requires information about wind direction, wind speed, and atmospheric diffusion coefficients. Wind data for our measurements are obtained from satellite resources (e.g., http://www.ssd.noaa.gov/VAAC) or from a nearby weather station located at El Tablón hill, about $10 \mathrm{~km}$ NW of the crater (3472 m a.s.l., see Fig. 1). The satellite service provides one velocity vector at the observed plume height. The weather station provides time-varying wind fields at groundlevel, which are not always representative of the plume conditions due to local topographic effects. Diffusion coefficients are derived from reliable plume width measurements obtained during traverses according to Eq. (2), which is derived from the above-mentioned Gaussian model.

$K_{h, v}=\left(\frac{w_{h, v}}{4}-b_{0}\right)^{2} \frac{u}{x}$

Here $K_{h, v}$ represents the diffusion coefficient, $w_{h, v}$ is the plume dimension (horizontal $-h$ - width or vertical $-v$ - thickness), $b_{0}$ is the crater radius $(\approx 300 \mathrm{~m}), u$ is the mean plume speed, and $x$ is the distance travelled by the plume from the vent to the scanning plane.

The complete processing routine, which allows us to determine the gas emission rates with only one scanning instrument, is performed automatically by our software. It typically takes $\sim 30$ min to analyze an 8-hour data set using a desktop PC.

\subsection{Errors}

According to Stoiber et al. (1983, pp. 428), the range of uncertainty involved in COSPEC measurements of a $\mathrm{SO}_{2}$ flux is \pm 13 to $\pm 23 \%$, and up to $\pm 42 \%$ in the worst case scenarios. This error is attributed primarily to poorly-constrained wind speed and direction ( $~ 80 \%$ of error, according to Stoiber et al., 1983). Another significant source of error, not traditionally accounted for, includes scattering effects due to ash or

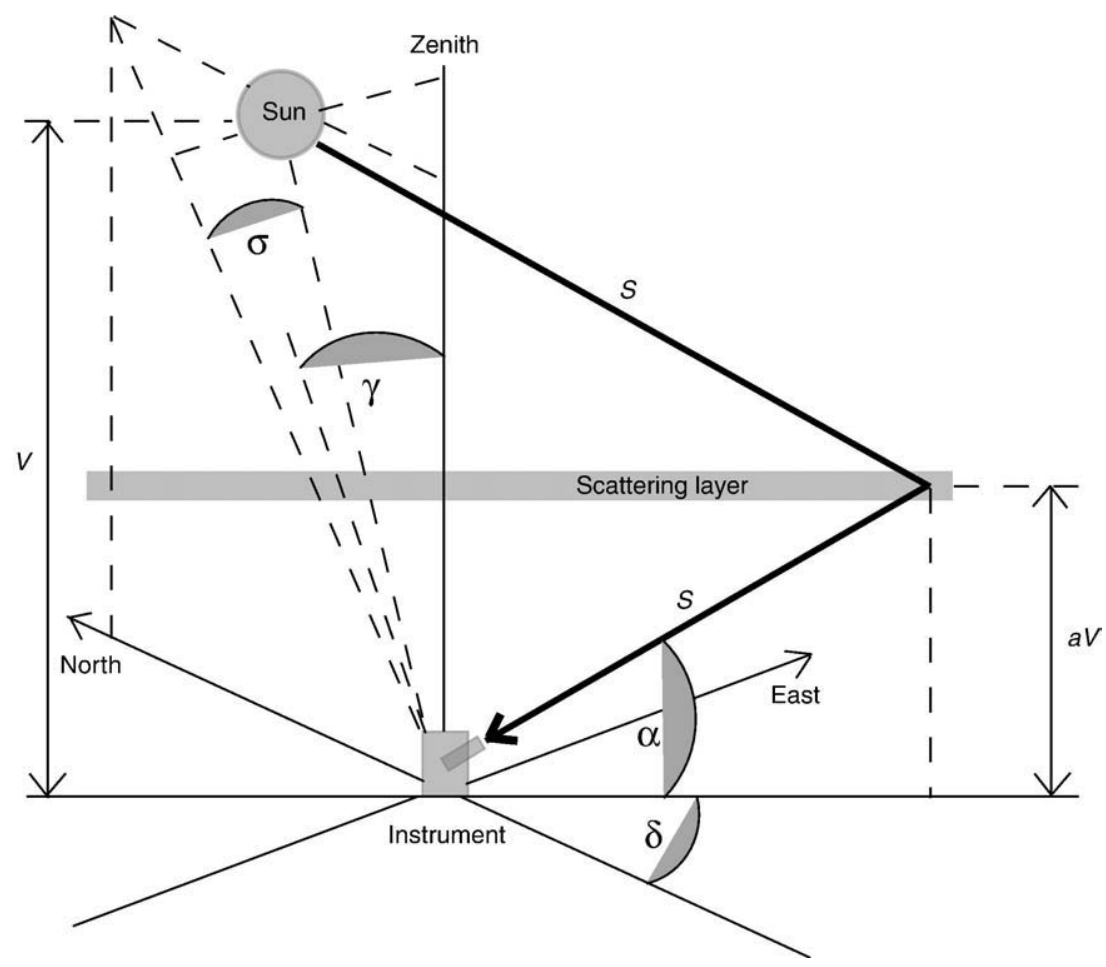

Fig. 3. Variable definition and schematics of the geometry involved in the Air Mass Factor calculation according for a first-order, single-scattering, radiative transfer model. 
Table 3

Prevalent conditions of volcanic plume, $\mathrm{SO}_{2}$ emission rate, and atmospheric injection of sulfur emitted by Tungurahua volcano

\begin{tabular}{|c|c|c|c|c|c|c|}
\hline & $\begin{array}{l}\text { Property } \\
\text { (units) }\end{array}$ & Range & Mean & $\begin{array}{l}\text { Standard deviation } \\
(\sigma)\end{array}$ & $\begin{array}{l}\text { Number of data points } \\
(n)\end{array}$ & $\begin{array}{l}\text { Typical error } \\
(\%)\end{array}$ \\
\hline \multirow[t]{5}{*}{ Plume } & Height (masl) & $3100-5800$ & 3638.66 & 662.19 & 612 & -5 to +10 \\
\hline & Horizontal length (m) & $200-14500$ & 7448.46 & 2348.68 & 91 & \pm 5 \\
\hline & Vertical length (m) & $50-4500$ & 2566.82 & 948.56 & 612 & \pm 10 \\
\hline & Speed $\left(\mathrm{m} \mathrm{s}^{-1}\right)$ & $0.5-16.5$ & 7.26 & 2.91 & 1231 & -5 to +30 \\
\hline & Direction $\left({ }^{\circ}\right)$ & $0-360$ & 250.42 & 60.17 & 1216 & \pm 5 (for deviations of $\pm 18^{\circ}$ ) \\
\hline \multirow{3}{*}{$\mathrm{SO}_{2}$ emission rate } & Complete period $\left(\mathrm{t} \mathrm{d}^{-1}\right)$ & $40-35000$ & 1457.65 & 2026.28 & 1091 & \pm 13 to $\pm 23(\text { COSPEC })^{a}$ \\
\hline & $\begin{array}{l}\text { Explosive degassing period } \\
\left(\mathrm{t} \mathrm{d}^{-1}\right)\end{array}$ & $151-35000$ & 2433.52 & 4623.73 & 62 & \pm 20 to $+36($ DOAS and mini-DOAS) \\
\hline & $\begin{array}{l}\text { Passive degassing period } \\
\left(\mathrm{t} \mathrm{d}^{-1}\right)\end{array}$ & $100-10808$ & 1391.09 & 1697.20 & 1029 & \\
\hline $\begin{array}{l}\text { Minimum injection of sulphur } \\
\text { into the atmosphere }\end{array}$ & \multicolumn{2}{|l|}{ Complete period $(\mathrm{t})$} & $1.91 \times 10^{6} \mathrm{t}$ & \multicolumn{3}{|c|}{1091 daily data points (during a period of $2615 \mathrm{~d}$ ) } \\
\hline
\end{tabular}

a Stoiber et al., 1983.

b Edmonds et al., 2003a,b; this work.

to dense vapor plumes, which can be as high as 70\% at typical measurement distances (Millán, 1980). Additionally, Andres and Schmid (2001) estimated that a COSPEC can only reliably measure $\mathrm{SO}_{2}$ burdens (within an accuracy of $10 \%$ ) at low visible wavelength opacities (less than $50 \%$ ).

For DOAS and mini-DOAS measurements, we refer to the analyses made by Edmonds et al. (2003b) who estimated a range of error of -20 to $+36 \%$ during an 8 -hour scanning period. Our error estimates are similar, although we employ a method to calculate the plume width using only one scanner. Moreover, the error contribution from uncertainties in wind direction data is about $\pm 10 \%$ for deviations of $\pm 30^{\circ}$ from the actual wind direction. The effect of UV scattering for distant plume targets has not been taken into account in these analyses. This effect becomes larger at shorter wavelengths (Mori et al., 2006) due primarily to elastic scattering processes (e.g., Rayleigh scattering cross section is proportional to $\lambda^{-4}$, where $\lambda$ represents wavelength), Consequently we focus on a spectral range of longer wavelengths (305-314 nm) for scaling with the reference spectrum, which sacrifices somewhat the lower detection limit. Our program computes an error factor for DOAS measurements according to the level of UV intensity (varying linearly from 0 for UV intensity attenuation of $50 \%$ with respect to the ideal theoretical value, to 1 for UV intensities equal to, or larger than, the theoretical value), and the plume-instrument distance (varying linearly from 0 for distances larger than $20 \mathrm{~km}$ to 1 for distances smaller than $1 \mathrm{~km}$ ). This factor is quantified as a percentage of the attenuation of what would be detected under ideal conditions (i.e., in a cloud-free atmosphere and with plume closer than $1 \mathrm{~km}$ from the instrument).

In addition to these sources of error, it is important to consider factors related to dispersal, or path, effects that influence volcanic plumes. Downwind $\mathrm{SO}_{2}$ depletion can occurs by oxidation to sulfuric acid via homogeneous and heterogeneous chemical processes, as well as by wet and dry deposition (Mather et al., 2004). We typically scan tropospheric plumes that have been airborne 200 to $5000 \mathrm{~s}$ since eruption (see Table 3). Assuming first-order chemical kinetics, we estimate that $\mathrm{SO}_{2}$ scrubbing associated with plume air time can cause an underestimation of the vent fluxes that are on the order of $0.02-0.6 \%$ for oxidation via gasphase, $>1-25 \%$ for aqueous-phase, and up to $2-50 \%$ for surface mechanisms (e.g., adsorption on volcanic ash particles, McGonigle et al., 2004). These gas-losses increase dramatically for ash-laden plumes or plumes passing through clouds or fog (where aerosol particle loading is greater than $100 \mu \mathrm{g} \mathrm{m}^{-3}$ ) and where total $\mathrm{SO}_{2}$ depletion can occur within the mentioned time scales. High insolation in equatorial latitudes will also promote plume photochemistry, which results in the removal of $\mathrm{SO}_{2}$ molecules.

Dry deposition models (Fujita et al., 2003) suggest $\mathrm{SO}_{2}$ settling velocities on the order of $1 \mathrm{~cm} \mathrm{~s}^{-1}$, which are too low to represent an important mechanism of gas removal prior to measurement. Conversely, wet deposition associated with rainfall seems to be a very efficient and rapid scavenging process (Fujita et al., 2003).
In contrast, scattering-induced enhancement of optical pathlengths in clouds (Pfeilsticker et al., 1998) or low-temperature $\mathrm{H}_{2} \mathrm{~S}$ oxidation to $\mathrm{SO}_{2}$ (Bluth et al., 1994) may counteract attenuating effects thereby producing overestimations of the initial $\mathrm{SO}_{2}$ venting. The interplay of these competitive processes results in a variable and complex error in the estimation of the gas flux. We have implemented algorithms during automatic monitoring and established operator controls during manual campaigns in an attempt to minimize uncertainties.

Finally, varying atmospheric conditions during the day cannot be resolved for short measurement intervals. Thus, extrapolation of inferred short-duration gas flux values can lead to error. The longer operation period of our DOAS system $\left(\sim 8 \mathrm{~h} \mathrm{~d}^{-1}\right)$, in comparison with that of previous techniques (e.g., $\sim 1 \mathrm{~h} \mathrm{~d}^{-1}$ for COSPEC campaigns), helps to minimize this kind of error.

\section{Results and data analysis}

\subsection{Size and evolution of the Tungurahua volcanic plumes}

Plume width (horizontal dimension perpendicular to the dispersal axis) data obtained from COSPEC and mini-DOAS traverses are shown in Table 3. These data correspond to the portion of the intercepted plume approximately $6 \mathrm{~km}$ downwind from the vent and have been corrected to correspond to a perpendicular transect. Plume thickness (vertical dimension) has been estimated from DOAS and stationary COSPEC measurements. Their statistics are also included in Table 3. The plume is normally detected at elevation angles between $13^{\circ}$ and $35^{\circ}$, with a mean value of $15.6^{\circ}$. Plume height corresponds to the altitude of the lower boundary of the plume at the interception plane.

The predominant winds in Ecuador are the Easterly Trade Winds, which govern the dispersion of Tungurahua volcanic plumes (Fig. 4). The transport of the volcanic emissions is also strongly affected by the high humidity coming from the nearby Amazon Basin and the surrounding topography. Also, gas measurements indicate a possible accumulation of stagnant gas over the Chambo River valley, and thus we avoid this area for plume monitoring.

Plume transport to the west $\left(250^{\circ}-290^{\circ}\right.$ azimuths $)$ dominates, representing $\sim 60 \%$ of the observations during the study period. About $10 \%$ of time, particularly during November and December of each year, westerly winds may dominate, preventing measurements with the DOAS system. Plume speed is considered comparable to the wind speed at the plume altitude. Wind speeds cluster around 5-9 $\mathrm{m} \mathrm{s}^{-1}$ (62\% of the data, Fig. 4 ).

Volcanic columns from Tungurahua have rarely reached the stratosphere; the notable exceptions are the most explosive eruptions at the end of 1999, and the 14 July and 16-17 August 2006 events (A. Krueger and S. Carn, 2006, pers. comm.). The emissions have been confined to the free troposphere and the boundary layer, producing recurrent ash fallout and acid rain over the nearby lands. Application of the Gaussian 
(a)

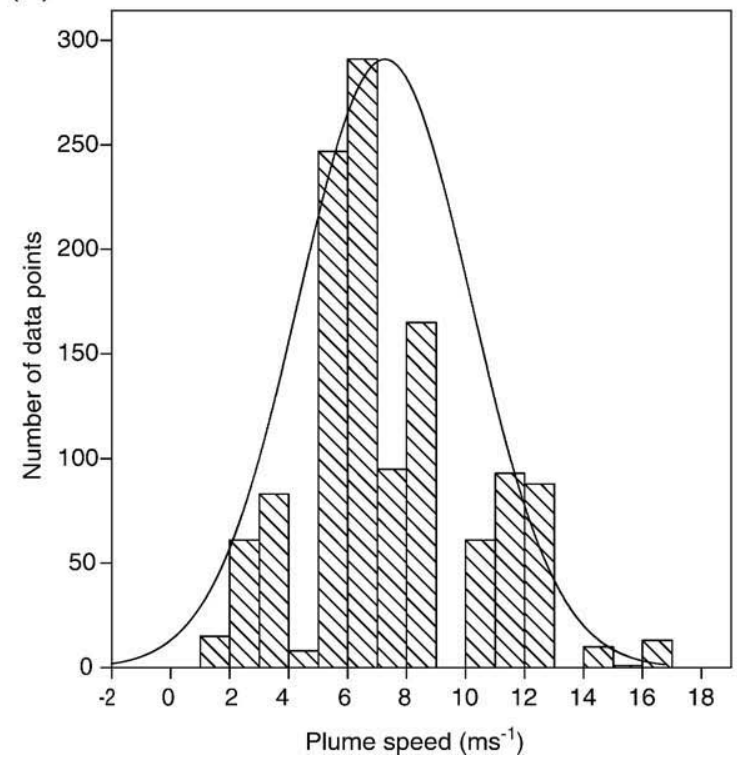

(b)

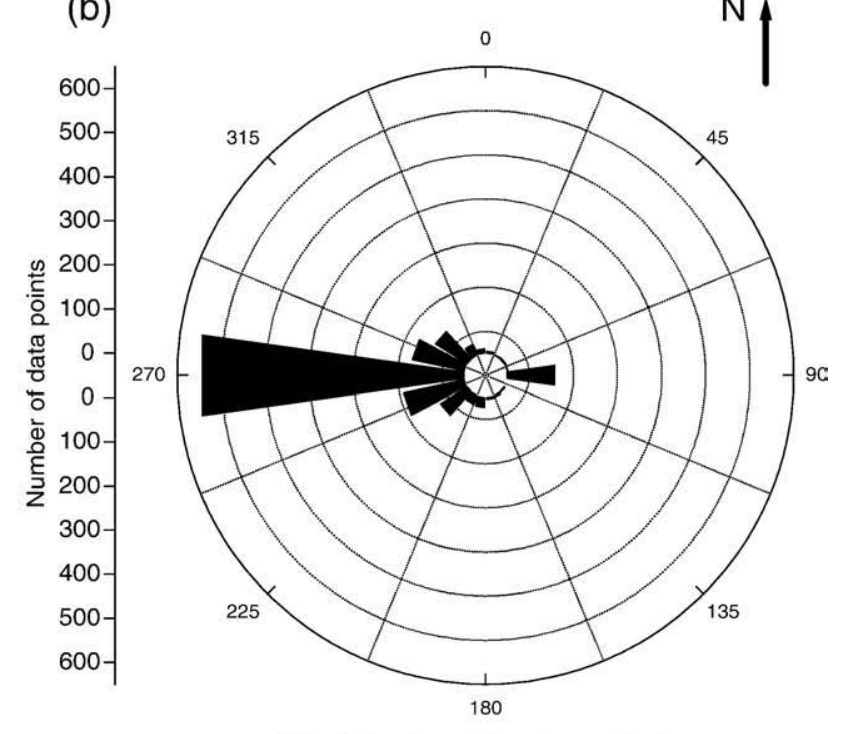

Wind direction at the plume altitude

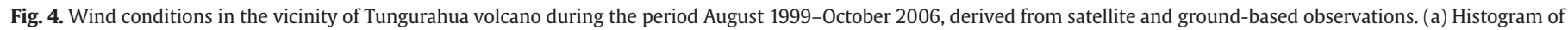
wind speed field and Gaussian distribution fit; (b) Rose diagram wind distribution summary at the plume altitude.

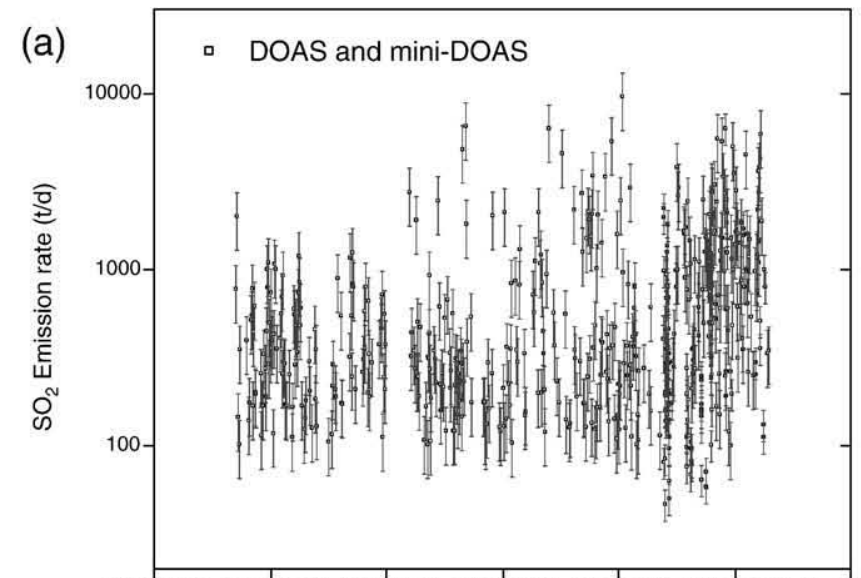

01/03/2004 01/09/2004 01/03/2005 01/09/2005 01/03/2006 01/09/2006 01/03/2007 Date $(\mathrm{dd} / \mathrm{mm} / \mathrm{yyyy})$

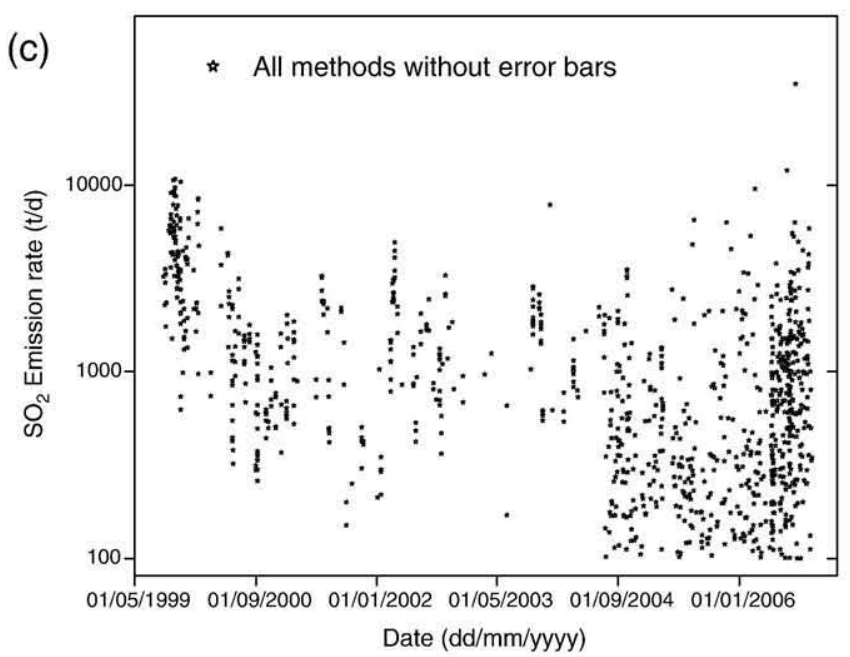

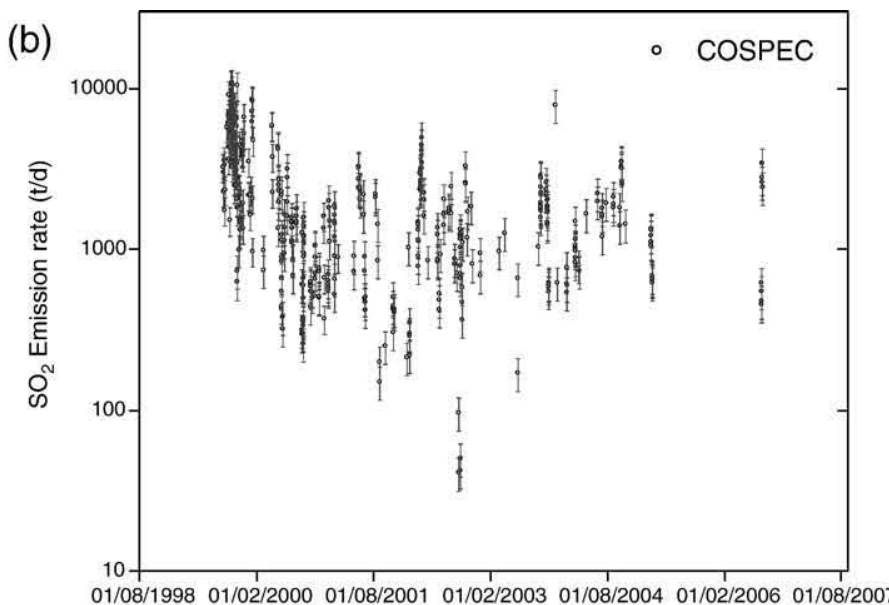

Date (dd/mm/yyyy)

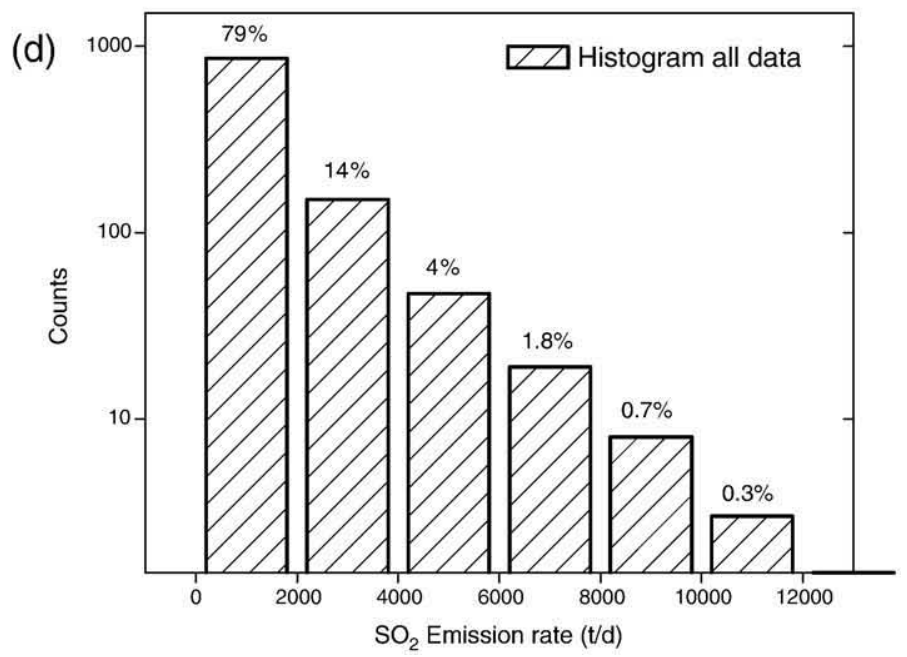

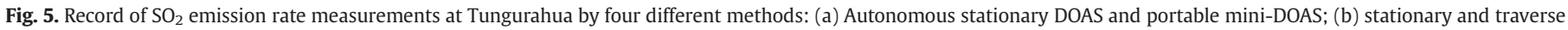

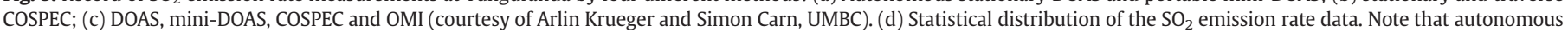
DOAS system has improved detection of weak plumes. 
advection-diffusion model (Eq. (2)) gives mean diffusivities of $\sim 3800$ and $\sim 530 \mathrm{~m}^{2} \mathrm{~s}^{-1}$ for the horizontal and vertical lengths of the plume, respectively, which are consistent with a Fickian diffusive process. Diffusion in the direction of transport is estimated to be a second order term compared to the wind force (U. Platt, 2007, pers. comm.).

\section{2. $\mathrm{SO}_{2}$ output and degassing modalities of Tungurahua volcano}

In the period between 27 August 1999 and 23 October 2006 (2615 days), a total of 1091 daily data points of the $\mathrm{SO}_{2}$ emission rate have been obtained by the IGEPN using the above-described groundbased techniques. Thus there are data for $42 \%$ of the 2615 days and $63 \%$ since the start of the 'DOAS era' in July 2004. The complete record is shown in Fig. 5 and Table 3 summarizes the results of our observations.

The 1999-2006 eruptive period of Tungurahua was characterized by alternating high- and low-activity phases. During high-activity phases, eruptive style was characterized by lava fountaining, Strombolian episodes, canon-like explosions, and light regional ash fallouts. These phases of activity are considered here to be an 'explosive' degassing style. In contrast, during low-activity phases, eruptive style was characterized by weaker gas emissions, with a limited amount of ash. Such phases are referred to here to be of 'passive' degassing.

In order to better understand these different degassing styles at Tungurahua, we compare the $\mathrm{SO}_{2}$ degassing rate with the Daily-cumulative Reduced Displacement (DRD), which is calculated from reduced displacement of individual events summed over a 24-hour period. Reduced displacement is a measure of distance-scaled seismic displacement and is often used as proxy for eruption intensity (McNutt, 1996).

Although reduced displacement is often used to characterize tremor, sub-surface events, or long-duration explosive eruptions (McNutt, 1996), we only consider explosion events, whose seismic signatures usually have short durations, to characterize different degassing styles.
This is because the reduced displacement is computed based on the maximum amplitude of the seismic signal without regard to its duration. We consider eruptive activity to be predominantly explosive if the corresponding DRD is $\geq 100 \mathrm{~cm}^{2}$. This value corresponds to an interval in which at least one typical explosion occurred each hour, given that typical reduced displacement values for individual explosions at Tungurahua are $4.75 \pm 2.65( \pm 1 \sigma) \mathrm{cm}^{2}$, based upon statistical analysis of 1063 events catalogued between September 1999 and October 2006. Such events were recorded by a seismic station (PATA) located at a distance of $4.64 \mathrm{~km}$ from the volcano summit. Data bias produced by sensor saturation or instrumental problems is considered minimal, and it does not significantly affect the eruption phase classification. Based upon this criterion we identified 86 days of energetic explosive activity, occurring in November 1999, May 2000, August 2001, September 2002, August-December 2003, July 2004, and May-August 2006. Gas emission data exist for 62 of these 86 days. A plot of DRD correlated with gas flux is presented in Fig. 6.

For explosive degassing periods (corresponding to 62 days of data), the mean $\mathrm{SO}_{2}$ emission rate is $2433 \pm 4623( \pm 1 \sigma) \mathrm{t} \mathrm{d}^{-1}$, whereas for passive degassing periods (corresponding to 1029 days), the mean emission rate is $1391 \pm 1697( \pm 1 \sigma) \mathrm{t} \mathrm{d}^{-1}$. Considering these average values, the explosive degassing periods emit 1.75 times as more gas than the passive degassing periods. A Student's $t$-Test applied to these two (independent) populations at the 0.05 confidence level shows that their mean values are different (Student's $t$-Test parameters $t=$ -3.94871, $p=8.42615 \times 10^{-5}$, Walpole et al., 2006).

The volcanic DRD threshold calculated at Tungurahua is an arbitrary scale, but is effective at broadly distinguishing between explosive and passive degassing phases. Transitional periods between the two modes of degassing tend to occur over many days and are not always neatly classified in either of the two sub-groups; nevertheless, the classification of explosive and passive degassing has enabled us to

(a)

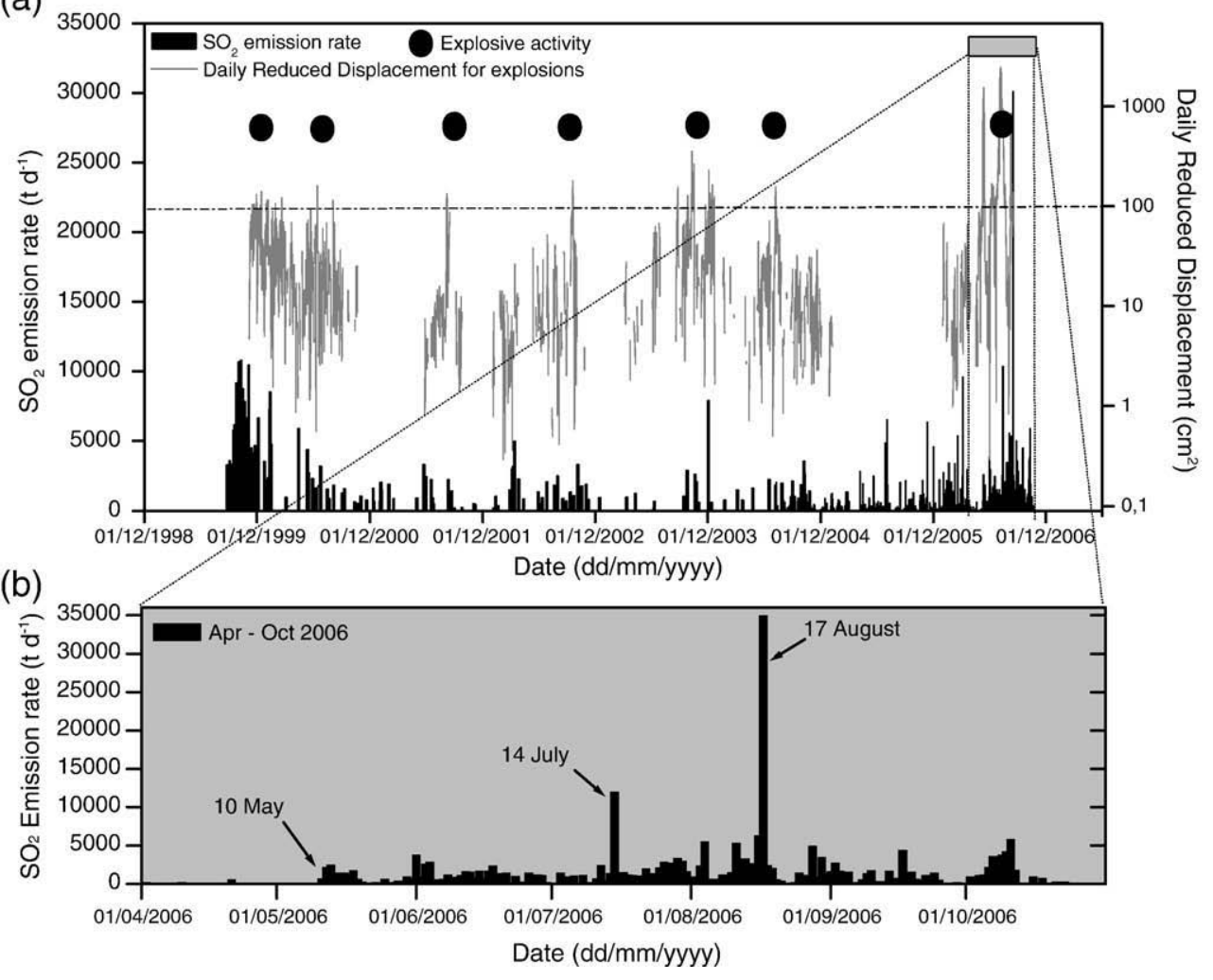

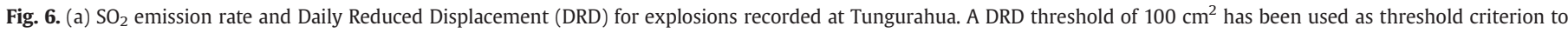

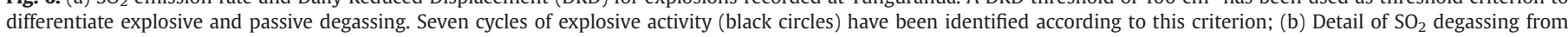
December 2005 to October 2006 showing peaks corresponding to explosive eruptions on 14 July and 16-17 August, 2006. 
identify a general correlation between eruptive intensity and $\mathrm{SO}_{2}$ output as seen with two different monitoring tools.

\section{Discussion}

\subsection{On the degassing mechanisms of Tungurahua}

Passive degassing has been observed during most of the study period ( 2458 of the 2615 days under scrutiny, i.e., 94\%) and accounts for $\sim 90 \%$ of the observed $\mathrm{SO}_{2}$ emission (1029 daily data points from the complete database of 1091 data). It has been observed that this gas emission pattern is usually not accompanied by large magma outputs (1999-2006 IGEPN reports) corresponding to large ash or tephra emissions or lava flows. From September 1999 to December 2004, a period dominated by passive degassing, Ruiz et al. (2006b) estimated that Tungurahua erupted a bulk magma volume of $2.6 \times 10^{7} \mathrm{~m}^{3}$ (i.e., $1.5 \times 10^{7} \mathrm{t}$ dense rock equivalent, DRE) in the form of tephra fall deposits. During the same period, a mean $\mathrm{SO}_{2}$ flux of $1592 \pm 1875$ $( \pm 1 \sigma) \mathrm{t} \mathrm{d}^{-1}$ (corresponding to 607 daily data points), is extrapolated to a total $\mathrm{SO}_{2}$ emission of $3.69 \times 10^{6} \mathrm{t}$ (i.e., $1.85 \times 10^{6} \mathrm{t}$ of $\mathrm{S}$ ). Assuming that the entire mass of erupted $\mathrm{SO}_{2}$ had been dissolved in the melt, a difference in sulfur content between non-degassed and degassed melts of $\sim 12 \mathrm{wt} . \%$ is necessary to reproduce the observed gas emissions. This difference does not account for other volatile sulfuric species (e.g., $\mathrm{H}_{2} \mathrm{~S}, \mathrm{~S}_{2}$ ), which might constitute an important portion of the liberated sulfur. The estimated amount of exsolved sulfur is at least two orders of magnitude larger than that predicted for a typical andesitic bulk composition (Oppenheimer, 2003).

Explosive degassing at Tungurahua, on the other hand, is associated with the emission of greater volumes of magma. For instance, $\sim 2500$ $500 \mathrm{ppm}$ sulfur content in the magma are required to reproduce the observed $\mathrm{SO}_{2}$ detected during the $14 \mathrm{July}\left(12,000 \mathrm{t} \mathrm{SO}_{2} ; 1 \times 10^{6} \mathrm{~m}^{3} \mathrm{DRE}\right)$ and for the 16 August $2006\left(35,000 \mathrm{t} \mathrm{SO}_{2} ; 2 \times 10^{7} \mathrm{~m}^{3} \mathrm{DRE}\right)$ eruptions. These sulfur concentrations are more reasonable for an andesitic magma (Oppenheimer, 2003).

Our observations suggest that syneruptive $\mathrm{SO}_{2}$ exsolution exceeds the corresponding volume of erupted melt, and that the erupted gas to melt ratio decreases with greater explosive activity.

Various explanations have been proposed to account for 'excessive' $\mathrm{SO}_{2}$ volcanic degassing, such as: the emission of pre-eruptive volatile phases present in the magma reservoir (Wallace and Gerlach, 1994); degassing from large bodies of magma intruded at shallow levels (Rose et al., 1982); breakdown of sulfur-bearing magmatic phases (Witter et al., 2005); mixing between reduced and oxidized magmas (Kress, 1997); assimilation of evaporite country rock (Goff et al., 1998); or fumarolic remobilization of native sulfur deposits (Witter et al., 2005). Petrological and geophysical analyses may be used to elucidate the question of which is the most suitable sulfur supply at Tungurahua. Some insight into the main plumbing system has already been revealed by geophysical studies.

Coupled with a tomographic seismic inversion method, Molina et al. (2005) found that the VT earthquake hypocenters recorded between August 1999 and May 2003 were tightly clustered along a vertical structure at depths between sea level and the summit crater (5023 $\mathrm{m}$ a.s.l.). They also found a high-P-wave velocity zone at the central base of the volcano under the vertically aligned hypocenters. These structures were interpreted by the authors as the shallow 'conduit' system and the source zone for a recharge 'reservoir', respectively. If a volatile phase exists at the reservoir depth $(5 \mathrm{~km})$, it would be composed of the less soluble species $\mathrm{CO}_{2}, \mathrm{H}_{2} \mathrm{O}$ (at contents $>3.81$ wt.\%), and $\mathrm{SO}_{2}$ (under oxidizing conditions; Scaillet et al., 1998). The gas volume fraction in the reservoir would likely be limited by the gas percolation threshold ( $30-70 \%$, Gaonac'h et al., 2003) that defines the point at which gas bubbles become interconnected to allow permeable gas flow through a bubble network.

To produce the relatively high $\mathrm{SO}_{2}$ emission rates of Tungurahua, a suitable gas-transport mechanism is needed. Two possibilities are considered here; gas flow through a permeable stagnant magma-filled conduit (Edmonds et al., 2003a), and gas escape from convective magma overturn in the conduit (Kazahaya et al., 1994; Stevenson and Blake, 1998).

In the first scenario, bubbles from the reservoir would rise up through the magma, but ascent speed of individual bubbles relative to typical andesitic magma is too low to constitute by itself an effective gas-melt segregation process (Sparks, 2003). However, during magma ascent, bubbles may grow by oversaturation-driven volatile diffusion and magma decompression (Proussevitch and Sahagian, 1998). If the gas percolation threshold is achieved, a 3-D vesicle network is developed, which allows an efficient gas escape mechanism. Increased viscosity of degassed magma may be sufficient to stop magma flow. Vesicle collapse or pore sealing (Edmonds et al., 2003a) will result in permeability drops and gas could accumulate creating a pressure gradient that promotes an increase in gas flux through permeable magma or through conduit walls. This feedback mechanism between permeability and pressure gradient could explain the explosions and short-lived lava fountains observed at Tungurahua. If at any stage, magma ascent is rapid enough to inhibit gas exsolution and escape, an explosive eruption of gas and magma may occur (Slezin, 2003). To guarantee sustained gas emissions according to this model, a free volatile phase must be available in the reservoir, because an unreplenished andesitic magma-filled conduit that is $\sim 20 \mathrm{~m}$ in diameter (typical value for andesitic stratovolcanoes, Witter et al., 2005; Ruiz et al., 2006a) and $\sim 5 \mathrm{~km}$ long (from geophysical studies, Molina et al., 2005), can only feed the observed $\mathrm{SO}_{2}$ fluxes for about 2 days. Moreover, degassed magma will accumulate progressively in the conduit impeding further eruptions.

In the second scenario non-erupted magma is recycled by convection within the conduit, due to density differences between descending gas-poor and ascending gas-rich magmas. Vesicle collapse is necessary in the portion of sinking magma to avoid the formation of a stable stratification in the conduit. Theoretical modelling (Stevenson and Blake, 1998) and field evidence (Kazahaya et al., 2002; Witter et al., 2005) suggest that convection is a feasible mechanism for passive degassing even in volcanoes with high-viscosity magmas. This process does not need, but is aided by, the existence of a volatile phase in the reservoir. To test this model, the conduit radius is calculated based on laminar flow theory in a vertical cylindrical conduit and experiments by Stevenson and Blake (1998) employing Eq. (3), which is derived taking into account the contribution of a gas phase located at the conduit base to the emitted flux. A description of the variables and their values is summarized in Table 4 .

$R_{c} \approx 4 \sqrt{\frac{\dot{m}_{\mathrm{SO}_{2}} \mu_{d}}{\left[\frac{\Delta C(1-\phi-\alpha)}{10^{6} M_{S}}+\frac{\left(X_{\mathrm{SO}_{2}}\right)^{2} g L \alpha}{R T_{c}}\right] M_{\mathrm{SO}_{2}} \rho_{c} \pi\left(R^{*}\right)^{2} \operatorname{Psg}\left(\rho_{d}-\rho_{c}\right)}}$

The fluid-dynamical input variables were constrained by using Conflow ${ }^{\circledR}$ version 1.0 .5 , a numerical program for evaluating steady magma flow and thermodynamic conditions in volcanic conduits (Mastin and Ghiorso, 2000). The Conflow ${ }^{\circledR}$ simulation predicts that the degassed magma viscosity varies between $9.23 \times 10^{3}$ and $1.16 \times 10^{4} \mathrm{~Pa} \mathrm{~s}$, and magma density ranges from 1720 to $2089 \mathrm{~kg} \mathrm{~m}^{-3}$, for ascending gas-bearing magma, and from 2423 to $2439 \mathrm{~kg} \mathrm{~m}^{-3}$, for descending gas-depleted magma. For a mean $\mathrm{SO}_{2}$ emission rate of $1391 \mathrm{t} \mathrm{d}^{-1}\left(16 \mathrm{~kg} \mathrm{~s}^{-1}\right)$, corresponding to passive degassing periods at Tungurahua, this model determines that conduit radius could vary from about 3.7 to $6.7 \mathrm{~m}$, values entirely plausible for this kind of volcano. Ruiz et al. (2006a) estimated a vent radius of $10 \mathrm{~m}$ for Tungurahua, based on oblique FLIR pictures taken in March 2003 (Samaniego et al., 2003). A viscosity ratio between ascending and descending magmas of about 30 corresponds to a flow regime in which downgoing blobs of degassed magma are encapsulated by the less viscous ascending magma, as suggested by Kazahaya et al. (2002) and Stevenson and Blake (1998). Furthermore, theoretical estimates of characteristic durations of vesicle collapse (Klug and Cashman, 
Table 4

Fluid-dynamical variables used to calculate the conduit radius supporting magma convection at Tungurahua volcano

\begin{tabular}{|c|c|c|c|c|c|}
\hline $\begin{array}{l}\text { Symbol } \\
\text { (units) }\end{array}$ & Value & Description & $\begin{array}{l}\text { Symbol } \\
\text { (units) }\end{array}$ & Value & Description \\
\hline \multicolumn{3}{|l|}{ Parameters } & \multicolumn{3}{|l|}{ Constants } \\
\hline$\overline{\dot{m}_{\mathrm{SO}_{2}}\left(\mathrm{~kg} \mathrm{~s}^{-1}\right)}$ & $16\left(1391 \mathrm{t} \mathrm{d}^{-1}\right)$ & Mass flux of $\mathrm{SO}_{2}$ & $R^{*}$ & 0.60 & $\begin{array}{l}\text { Ratio of radius of up-welling magma to } \\
\text { radius of conduit }^{c}\end{array}$ \\
\hline$\Delta \mathrm{C}(\mathrm{ppm} \mathrm{m})$ & $100-1000$ & $\begin{array}{l}\text { Difference in gas mass fraction between chamber } \\
\text { and degassed magma }{ }^{a}\end{array}$ & PS & 0.064 & Poiseuille number ${ }^{c}$ \\
\hline$X_{\mathrm{SO}_{2}}(\mathrm{~mol} \%)$ & $0-7$ (at 30 vol.\%) & $\mathrm{SO}_{2}$ gas molar fraction in chamber ${ }^{\mathrm{b}}$ & $M_{\mathrm{SO}_{2}}\left(\mathrm{~kg} \mathrm{~mol}^{-1}\right)$ & 0.064 & Molecular weight of $\mathrm{SO}_{2}$ \\
\hline$L(\mathrm{~m})$ & 5000 & Conduit length & $M_{S}\left(\mathrm{~kg} \mathrm{~mol}^{-1}\right)$ & 0.032 & Molecular weight of S \\
\hline & & & $g\left(\mathrm{~m} \mathrm{~s}^{-2}\right)$ & 9.81 & Gravitational acceleration \\
\hline & & & $\mathrm{R}\left(\mathrm{J} \mathrm{K}^{-1} \mathrm{~mol}^{-1}\right)$ & 8.31 & Ideal gas constant \\
\hline \multicolumn{3}{|l|}{ Inputs for Conflow ${ }^{\circledR}$} & \multicolumn{3}{|c|}{ Outputs from Conflow® } \\
\hline $\mathrm{H}_{2} \mathrm{O}$ (wt.\%) & $3.81-6.05$ & Weight percent of water in mixture ${ }^{\mathrm{d}}$ & $\mu_{c}($ Pa s) & $300 ; 400$ & Viscosity of ascending gas-bearing magma ${ }^{\mathrm{g}}$ \\
\hline$\phi(\mathrm{vol} . \%)$ & 30 & Crystal volume fraction (mainly plagioclase) $^{\mathrm{e}}$ & $\mu_{d}(\mathrm{~Pa} \mathrm{~s})$ & $9.23 \times 10^{3} ; 1.16 \times 10^{4}$ & Viscosity of descending degassed magma ${ }^{\mathrm{g}}$ \\
\hline$\alpha(\operatorname{vol} . \%)$ & $0-30$ & Gas volume fraction in chamber ${ }^{\mathrm{b}}$ & $\rho_{c}\left(\mathrm{~kg} \mathrm{~m}^{-3}\right)$ & $2089 ; 1720$ & Density of ascending gas-bearing magma ${ }^{\mathrm{g}}$ \\
\hline$T_{c}(\mathrm{~K})$ & 1373 & Magma temperature in chamber ${ }^{\mathrm{a}}$ & $\rho_{d}\left(\mathrm{~kg} \mathrm{~m}^{-3}\right)$ & $2439 ; 2423$ & Density of descending degassed magma ${ }^{g}$ \\
\hline$p(\mathrm{~Pa})$ & $1.30 \times 10^{8}$ & Pressure at depth ( $5 \mathrm{~km}$ below crater) & & & \\
\hline $\mathrm{SiO}_{2}(\mathrm{wt} . \%)$ & 58.60 & Weight percent of oxides in melt (anhydrous) ${ }^{f}$ & $R(\mathrm{~m})$ & $3.7-6.7$ & Conduit radius ${ }^{\mathrm{g}}$ \\
\hline $\mathrm{Fe}_{2} \mathrm{O}_{3}+\mathrm{FeO}($ wt.\%) & 7.52 & & & & \\
\hline $\mathrm{MgO}$ (wt.\%) & 4.54 & & & & \\
\hline $\mathrm{CaO}$ (wt.\%) & 6.42 & & & & \\
\hline $\mathrm{TiO}_{2}$ (wt.\%) & 0.91 & & & & \\
\hline $\mathrm{Na}_{2} \mathrm{O}$ (wt.\%) & 3.69 & & & & \\
\hline $\mathrm{K}_{2} \mathrm{O}$ (wt.\%) & 1.84 & & & & \\
\hline $\mathrm{MnO}$ (wt.\%) & 0.12 & & & & \\
\hline $\mathrm{P}_{2} \mathrm{O}_{5}$ (wt.\%) & 0.28 & & & & \\
\hline
\end{tabular}

References and notes

${ }^{\text {a}}$ Typical values for andesite reported by Oppenheimer (2003).

${ }^{\mathrm{b}}$ Typical values for andesite reported by Wallace (2001).

${ }^{\mathrm{c}}$ After experiments by Stevenson and Blake (1998).

${ }^{d}$ Equivalent to a gas volume fraction in chamber from $0 \%$ (water saturated magma) to $30 \%$.

eFrom unpublished analyses by P. Samaniego, 2006.

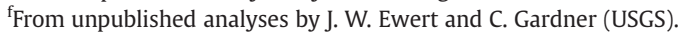

${ }^{\mathrm{g}}$ First value corresponds to a gas volume fraction in chamber of $0 \%$, second to $30 \%$ (calculated at depth where a magma void fraction of $70 \%$ is achieved).

1996) and the onset of convection (Stevenson and Blake, 1998) for Tungurahua's magma give values $\sim 10 \mathrm{~s}$ and $\sim 5 \mathrm{~s}$, respectively. Carrigan et al. (1992) invoke a similar driving mechanism to explain how very viscous magmas reach the Earth's surface. In their model, ascent of a viscous magma is "lubricated" by encapsulation in a less viscous magma. In our case, the less viscous component is simply magma with gas in solution. Observations of lava fountaining, and considerations of the relative fluidity of lavas at Tungurahua, suggest that convective overturn in the conduit is potentially viable. We consider that magma overturn may occur intermittently to recharge a previously stagnant permeable magma, thus the two competing models are not mutually exclusive processes at Tungurahua.

According to our models, minor explosive activity at Tungurahua can be predicted by real-time $\mathrm{SO}_{2}$ monitoring. For both $\mathrm{SO}_{2}$ eruption mechanisms, gas flux is modulated by conduit permeability at shallow levels, under steady-state conditions. Thus, we propose that significant and rapid drops in gas emissions may result in explosions. For dangerous explosive eruptions emplacement of considerable amounts of gas-rich magma is required at the recharge zone. Explosive activity would then need only a few hours to be established, given pertinent magma rise velocities ( $1 \mathrm{~m} \mathrm{~s}^{-1}, \mathrm{H}$. Kumagai, 2007, pers. comm.) and conduit lengths $(\sim 5 \mathrm{~km})$. This behaviour was noted at Tungurahua during the two major eruptions on 14 July and 16-17 August 2006 (Fig. 6), which were heralded by sustained $\mathrm{SO}_{2}$ emissions during the two previous months and by a sudden increment in $\mathrm{SO}_{2}$ emissions coincident with the actual eruptions.

\subsection{On the lifetime of sulfuric emissions of Tungurahua}

For the 7-year period (1999-2006), cumulative emission of $\mathrm{SO}_{2}$ totalled $3.81 \times 10^{6} \mathrm{t}$, equivalent to at least $1.91 \times 10^{6} \mathrm{t}$ of sulfur injected into the atmosphere. Most of the emissions were transported to the west of Tungurahua at tropospheric altitudes (Table 3). According to Stevenson et al. (2003), who used a global three-dimensional chemistry-transport model to investigate the tropospheric sulfur cycle, mean lifetime for $\mathrm{SO}_{2}$ at equatorial latitudes and for Tungurahua plume altitudes ranges between 2 and 5 days, and the mean lifetime of $\mathrm{SO}_{4}$ aerosols is less than 5 days. High humidity, presence of ash in the plume, and high radiant flux in the zone tend to decrease these mean lifetimes. Based upon satellite observations of plume dispersion, we estimate that a $\mathrm{SO}_{2}$ mean lifetime of about 1 day is most representative for Tungurahua emissions (A. Krueger, 2006, pers. comm.).

\section{Conclusions}

We report measurements of the $\mathrm{SO}_{2}$ emission rate of Tungurahua volcano obtained by COSPEC, DOAS, and mini-DOAS campaigns in stationary and car-traverse modes during the August 1999 to October 2006 interval. We suggest that implementation of a robust, hightemporal resolution, automatic DOAS system can provide reliable records of the intensity of degassing at Tungurahua. Data analysis has been improved by incorporating single-scattering, geometrical radiative transfer modelling that considers frequent cloudy conditions, and one-dimensional advection-diffusion equations into a semi-automatic processing routine. Post-processing validation confirms the reliability of the results and helps to identify other potential sources of error.

During the entire study period of 86 months, the mean $\mathrm{SO}_{2}$ emission rate was $1458 \mathrm{t} \mathrm{d}^{-1}$ and the total sulfur emission was of at least $1.91 \mathrm{Mt}$. The rate of degassing of sulfur at Tungurahua, especially through passive emissions, requires $\mathrm{SO}_{2}$ exsolution of an andesitic magma volume that is two orders of magnitude larger than that determined by the observed 
eruption rate. We consider as explanations for this discrepancy that the magma degasses efficiently from depth either by permeable flow, or by convection in the conduit, or by both processes.

During the most explosive phases (average flux of $2434 \mathrm{t} \mathrm{d}^{-1}$ ) the magma eruption rate is commensurate with what would be expected for common $\mathrm{SO}_{2}$-rich andesitic magmas. This suggests that the primary degassing modes are controlled by variations in the magma ascent rate and conduit permeability, which influences gas segregation processes leading to passive emissions; or to gas retention processes causing overpressure build-ups and potential explosive eruptions. Monitoring of outgassing by real-time $\mathrm{SO}_{2}$ measurements may thus help to better predict paroxysmal eruption timing.

\section{Acknowledgements}

We acknowledge the generous donation of a COSPEC V by the Canadian International Development Agency (CIDA) and help from Professor Stanley Williams (Arizona State University). The DOAS system was financed by Ecuador's Governmental FUNDACYT institution and was installed with the guidance and cooperation of Peter Dunkley, Marie Edmonds, Richard Herd, Vicky Hards, and Graham Ryan of the Montserrat Volcano Observatory, and the British Embassy in Quito. We also thank Clive Oppenheimer (University of Cambridge) for his support for the mini-DOAS. Arlin Krueger and Simon Carn (University of Maryland) are acknowledged for their help with OMI data during periods of volcanic crisis. Data presented here were collected and processed daily by members of the OVT staff. The authors thank two anonymous reviewers and the Guest Editor for their critical comments that have greatly improved this manuscript.

\section{References}

Andres, R.J., Schmid, J.W., 2001. The effects of volcanic ash on COSPEC measurements. Journal of Volcanology and Geothermal Research 108, 237-244.

Arellano, S., Hall, M., Ayala, E., 2006. Spectroscopic remote sensing of volcanic gases: the Ecuadorian case. Pure and Applied Optics 39 (1), 99-108.

Bluth, G., Scott, C., Sprod, I., Schnetzle, C., Krueger, A., Walter, L., 1994. Explosive $\mathrm{SO}_{2}$ emissions from the 1992 eruptions of Mount Spurr, Alaska. In: Keith, T. (Ed.), Spurr 1992. United States Geological Survey Bulletin, vol. 2139, pp. 37-45.

Bursik, M., 1998. Tephra dispersal. In: Gilbert, J.S., Sparks, R.S.J. (Eds.), The Physics of Explosive Volcanic Eruptions. Geological Society Special Publications, London, vol.145, pp. 115-144.

Carn, S.A., Krueger, A., Arellano, S., Krotkov, N., Yang, K., 2008. Daily monitoring of Ecuadorian volcanic degassing from space. Journal of Volcanology and Geothermal Research, doi: 10.1016/j.jvolgeores.2008.01.029, this issue.

Carrigan, Ch., Schubert, G., Eichelberger, J., 1992. Thermal and dynamical regimes of singleand two-phase magmatic flow in dikes. Journal of Geophysical Research 97 (B12) 17377-17392.

Edmonds, M., Oppenheimer, C. Pyle, D., Herd, R., Thompson, G, 2003a. $\mathrm{SO}_{2}$ emissions from Soufriére Hills Volcano and their relationship to conduit permeability, hydrothermal interaction and degassing regime. Journal of Volcanology and Geothermal Research 124, 23-43.

Edmonds, M., Herd, R., Galle, B., Oppenheimer, C., 2003b. Automated, high timeresolution measurements of $\mathrm{SO}_{2}$ at Soufriére Hills Volcano, Montserrat. Bulletin of Volcanology 65, 578-586.

Fujita, S., Sakurai, T., Matsuda, K., 2003. Wet and dry deposition of sulfur associated with the eruption of Miyakejima volcano, Japan. Journal of Geophysical Research 108 (D15), 4444. doi:10.1029/2002JD003064

Galle, B., Oppenheimer, C., Geyer, A., McGonigle, A., Edmonds, M., Horrocks, L., 2002. A miniaturized ultraviolet spectrometer for remote sensing of $\mathrm{SO}_{2}$ fluxes: a new too for volcano surveillance. Journal of Volcanology and Geothermal Research 119, 241-254.

Gaonac'h, H., Lovejoy, S., Schertzer, D., 2003. Percolating magmas and explosive volcanism. Geophysical Research Letters 30 (11), 1559. doi:10.1029/2002GL016022.

Goff, F., Janik, C.J., Delgado, H., Werner, C., Counce, D., Stimac, J.A., Siebe, C., Love, S.P., Williams, S.N., Fischer, T., Johnson, L., 1998. Geochemical surveillance of magmatic volatiles at Popocatépetl Volcano, Mexico. Geological Society of America Bulletin 110 (6), 695-710

Hall, M.L., Robin, C., Beate, B., Mothes, P., Monzier, M., 1999. Tungurahua volcano Ecuador: structure, eruptive history and hazards. Journal of Volcanology and Geothermal Research 91, 1-21.

Hall, M., Robin, C., Samaniego, P., Monzier, M., Eissen, J.-P., Mothes, P., Yepes, H., von Hillebrandt, C., Beate, B., 2002. Mapa de peligros potenciales del Volcán Tungurahua (in Spanish). Scale: 1:50000. Edited by IGEPN-IRD-IGM, Quito, 1.

Hönninger, G., von Friedeburg, C., Platt, U., 2004. Multi axis differential optical absorption spectroscopy. Atmospheric Chemical Physics 4, 231-254.

Kazahaya, K., Shinohara, H., Saito, G., 1994. Excessive degassing of Izu-Oshima volcano: magma convection in a conduit. Bulletin of Volcanology 56, 207-216.
Kazahaya, K., Shinohara, H., Saito, G., 2002. Degassing processes of Satsuma-Iwojima volcano, Japan: supply of volatile components from a deep magma chamber. Earth, Planets, Space 54, 327-335

Klug, C., Cashman, K., 1996. Permeability development in vesiculaing magmas: implications for fragmentation. Bulletin of Volcanology 58, 87-100.

Kress, V., 1997. Magma mixing as a source for Pinatubo sulfur. Nature 389, 591-593.

Le Pennec, J.-L., Jaya, D., Samaniego, P., Ramón, P., Moreno, S., Egred, J., van der Plicht, J., 2008. The AD 1300-1700 eruptive periods at Tungurahua volcano, Ecuador revealed by historical narratives, stratigraphy and radiocarbon dating, Journal of Volcanology and Geothermal Research, this issue.

Martínez, A., 1886. Report in the La Nación newspaper (in Spanish), 17 March 1886, Guayaquil.

Martínez, N., 1932. Las grandes erupciones del Tungurahua de los años 1916-1918 (in Spanish). Publicaciones del Observatorio Astronómico de Quito, Sección Geofísica, Quito, Ecuador. 100 pp.

Mastin, L., Ghiorso, M., 2000. A numerical program for steady-state flow of magma-gas mixtures through vertical eruptive conduits. United States Geological Survey OpenFile Report, Vancouver, Washington, pp. 00-209.

Mather, T., Tsanev, V., Pyle, D., McGonigle, A., Oppenheimer, C., Allen, A., 2004. Characterization and evolution of tropospheric plumes from Lascar and Villarica volcanoes, Chile. Journal of Geophysical Research 109 (D21303). doi:10.1029/ 2004JD004934.

McGonigle, A., Oppenheimer, C., 2003. Optical sensing of volcanic gas and aerosol emissions. In: Oppenheimer, C., Pyle, D., Barclay, J. (Eds.), Volcanic Degassing. Geological Society Special Publications, London, vol. 213, pp. 149-168.

McGonigle, A., Oppenheimer, C., Galle, B., Mather, T., Pyle, D., 2002. Walking traverse and scanning DOAS measurements of volcanic gas. Geophysical Research Letters 29, 46-1-46-4. doi:10.1029/2002gl015827.

McGonigle, A., Delmelle, P., Oppenheimer, C., Tsanev, V., Delfosse, T., Williams-Jones, G., Horton, K., Mather, T., 2004. $\mathrm{SO}_{2}$ depletion in tropospheric volcanic plumes. Geophysical Research Letters 31 (LI3201). doi:10.1029/2004GL019990.

McNutt, S., 1996. Seismic monitoring and eruption forecasting of volcanoes: a review or the state-of-the-art and case histories. In: Scarpa, R., Tilling, R. (Eds.), Monitoring and Mitigation of Volcano Hazards. Springer-Verlag. Berlin-Heidelberg, pp. 100-146.

Millán, M., 1980. Remote sensing of air pollutants: a study of some atmospheric scattering effects. Atmospheric Environment 14, 1241-1253.

Moffat, A.-J., Millán, M., 1971. The application of optical correlation techniques to the remote sensing of $\mathrm{SO}_{2}$ plumes using skylight. Atmospheric Environment 5, 677-690.

Molina, I., Kumagai, H., Le Pennec, J.-L., Hall, M., 2005. Three-dimensional P-wave velocity structure of Tungurahua volcano, Ecuador. Journal of Volcanology and Geothermal Research 147, 144-156.

Mori, T., Mori, T., Kazahaya, K., Ohwada, M., Hirabayashi, J., Yoshikawa, S., 2006. Effect of UV scattering on $\mathrm{SO}_{2}$ emission rate measurements. Geophysical Research Letters 33 (L17315). doi:10.1029/2006GL026285.

Oppenheimer, C., 2003. Volcanic Degassing. In: Rudnick, R.L. (Editor), The Crust. Treatise on Geochemistry Vol. 3 (Holland, H.D., and Turekian, K.K., Editors). ElsevierPergamon, Oxford, 123-166.

Pfeilsticker, K., Erle, F., Funk, O., Marquard, L., Wagner, T., Platt, U., 1998. Optical path modifications due to tropospheric clouds: implications for zenith sky measurements of stratospheric gases. Journal of Geophysical Research 103 (D19), 25323-25335.

Platt, U., 1994. Differential optical absorption spectroscopy. In: Sigirst, M. (Ed.), Air monitoring by spectroscopic techniques. John Wiley \& Sons, Hoboken, N.J., pp. 27-84.

Proussevitch, A., Sahagian, D., 1998. Dynamics and energetics of bubble growth in magmas: analytical formulation and numerical modelling. Journal of Geophysical Research 103 (B8), 18223-18251.

Robock, A., 2000. Volcanic eruptions and climate. Reviews of Geophysics 38 (2), 191-219. Rose, W., Stoiber, R., Malinconico, L., 1982. Eruptive gas compositions and fluxes of explosive volcanoes; budget of $\mathrm{S}$ and $\mathrm{Cl}$ emitted from Fuego Volcano, Guatemala. In: Thorpe, R.S. (Ed.), Andesites; Orogenic Andesites and Related Rocks. John Wiley, New York, pp. 669-676

Ruiz, M., Hall, M., Samaniego, P., Ruiz, G., Villagómez, D., 1999. Seismic activity in Tungurahua Volcano: correlation between tremor and precipitation rates. Proceedings of the Fourth International Symposium on Andean Geodynamics, Göttingen, pp. 636-639.

Ruiz, M., Lees, J., Johnson, J., 2006a. Source constraints of Tungurahua volcano explosion events. Bulletin of Volcanology 68, 480-490.

Ruiz, A., Le Pennec, J.-L., Palacios, E., Hall, M., Yepes, H., 2006b. Indirect estimation of ash fall volume deposited near Tungurahua volcano (Ecuador) from Oct. 1999 to Dec. 2004. Proceedings of the Fourth Conference Cities on Volcanoes IAVCEI, Quito, p. 27.

Samaniego, P., Eissen, J.-P., Le Pennec, J.-L., Hall, M., Monzier, M., Mothes, P., Ramón, P., Robin, C., Egred, J., Molina, I., Yepes, H., 2003. Los Peligros Volcánicos Asociados con el Tungurahua (in Spanish). Corporación Editora Nacional, IGEPN, IRD, Quito. 108 pp.

Scaillet, B., Clemente, B., Evans, B., Pichavant, M., 1998. Redox control of sulfur degassing in silicic magmas. Journal of Geophysical Research 103 (B10), 23937-23949.

Slezin, Y.B., 2003. The mechanism of volcanic eruptions (a steady state approach). Journal of Volcanology and Geothermal Research 122 (1-2), 7-50.

Sparks, R.S.J., 2003. Dynamics of magma degassing. In: Oppenheimer, C., Pyle, D., Barclay, J. (Eds.), Volcanic Degassing. Geological Society Special Publications, London, vol. 213, pp. 5-22.

Stevenson, D., Blake, S., 1998. Modelling the dynamics and thermodynamics of volcanic degassing. Bulletin of Volcanology 60, 307-317.

Stevenson, D., Johnson, C., Collins, W., Derwent, R., 2003. The tropospheric sulphur cycle and the role of volcanic $\mathrm{SO}_{2}$. In: Oppenheimer, C., Pyle, D., Barclay, J. (Eds.), Volcanic Degassing. Geological Society Special Publications, London, vol. 213, pp. 295-305.

Stoiber, R., Malinconico, L., Williams, S., 1983. Use of the correlation spectrometer at volcanoes. In: Tazieff, H., Sabroux, J.-C. (Eds.), Forecasting volcanic events. Elsevier, Amsterdam, pp. 425-444. 
Vandaele, A.C., Simon, P.C., Guilmot, J.M., Carleer, M., Colin, R., 1994. $\mathrm{SO}_{2}$ absorption cross section measurements in the UV using a Fourier transform spectrometer. Journal of Geophysical Research 99, 25599-25605.

Wallace, P., 2001. Volcanic $\mathrm{SO}_{2}$ emissions and the abundance and distribution of exsolved gas in magma bodies. Journal of Volcanology and Geothermal Research 108, 85-106.

Wallace, P., Gerlach, T., 1994. Magmatic vapor source for the sulfur dioxide released during volcanic eruptions: evidence from Mount Pinatubo. Science 265, 497-499.
Walpole, R., Myers, R., Myers, S., Ye, K., 2006. Probability \& Statistics for Engineers \& Scientists, Eighth ed. Prentice Hall, New Jersey. 848 pp.

Witter, J.B., Kress, V.C., Newhall, C., 2005. Volcán Popocatépetl, Mexico. Petrology, magma mixing and immediate sources of volatiles for the 1994-present eruption. Journal of Petrology 46, 2337-2366. 